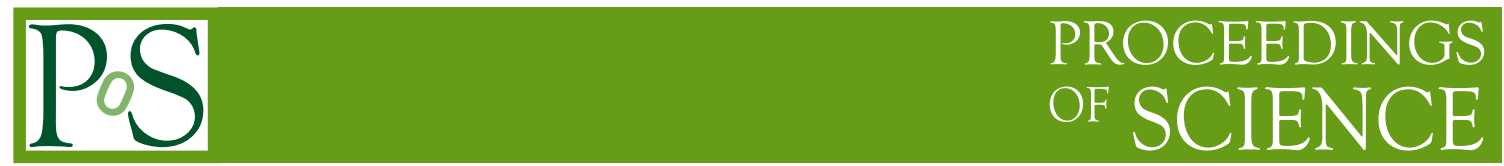

\title{
Geometrical aspects of deformation quantization
}

\author{
Pierre Bieliavsky* \\ Université Catholique de louvain \\ E-mail: pierre.bieliavskyegmail.com
}

This talk will be an introduction to deformation quantization based on geometrical considerations. I will show how the notion of $*$-product emerges from a formula for the multiplication of matrices. I will then give a definition of deformation quantization in the context of Poisson manifolds and conclude by general results about this notion. The talk is meant to a general audience.

Frontiers of Fundamental Physics 14 - FFP14,

15-18 July 2014

Aix Marseille University (AMU) Saint-Charles Campus, Marseille

${ }^{*}$ Speaker. 